九州大学学術情報リポジトリ

Kyushu University Institutional Repository

\title{
A GIS-based Supply and Demand Potential Mapping of Forestry-bioenergy : A Case Study of the Yongdong Region, Gangwon, South Korea
}

Lee, Jung-soo

Department of Forest Management, College of Forest and Environmental Sciences, Kangwon National University

Yoshida, Shigejiro

Forest Management, Agro-environmental Sciences, Faculty of Agriculture

https://doi.org/10.5109/22073

出版情報：九州大学大学院農学研究院紀要. 57 (1)，pp.201-210，2012-02. Faculty of Agriculture， Kyushu University

バージョン：

権利関係: 


\title{
A GIS-based Supply and Demand Potential Mapping of Forestry-bioenergy: A Case Study of the Yongdong Region, Gangwon, South Korea
}

\author{
Jung-Soo LEE ${ }^{1 *}$ and Shigejiro YOSHIDA \\ Laboratory of Forest Management, Division of Forest Sciences, Department of \\ Agro-environmental Sciences, Faculty of Agriculture, \\ Kyushu University, Fukuoka 812-8581, Japan \\ (Received October 31, 2011 and accepted November 9, 2011)
}

\begin{abstract}
This study purposes to construct supply and demand potential map of forest bioenergy with a GISbased decision support system. The target areas of this study were a part of the forests in Yongdong region, Gangwondo, South Korea and major forest types were pinus densiflora, pinus koreaiansis, and Oak. Data about forest type, age classes, the number of households, regional silviculture planning was stored in GIS to define the potential areas for supplying potential bioenergy from the forests, and to assess biomass available for a household. The number of detached house (about 40,000) represent $74 \%$ of total house. Quantity of total annual energy demand in 4 Cities was about 960,000 Gcal. Theoretical total quantity of forest biomass supply was 40,646 ton from the silviculture planning for 10 years, and average value per ha was 0.53 ton. The available quantity of supply for the forest biomass energy of chip was about $86,000 \mathrm{Gcal}$, and on average 1.29 Gcal per ha could be supplied. However, the supply rate of forest bioenergy on Cities was about $1 \%$, and differences of energy supply rate based on fuel forms were $0.08 \%$. The supply rate of chipfuel was the highest in GS about 1.26\%, and for Yang yang, Gang neung, Sam cheok $0.90 \%, 0.77 \%$ and $0.75 \%$ respectively. Also, the supply rate for pellet has showed similar tendency with chip form.
\end{abstract}

Key words: forestry-bioenergy, GIS, potential mapping

\section{INTRODUCTION}

In responding to the climate change such as global warming, many researches and investments are being carried out for the reduction of greenhouse gas emission. Among them, the forest are getting attention as environmental-friendly green resources, and also be cause of their potential for utilization of unused wood materials (Korea Forest Service, 2009).

Action of green energy plan in EU, establishment of PURPA (Public Utility Regulatory Act) in the United States of America, wood fuel production plans in Finland, and carbon tax and policy of increasing forest fuel production in Sweden are represented as typical movements. Especially, use of renewable energy such as water power, wind power, and biomass are actively recommended in EU, and among renewable sources use of biomass energy is the most important. Establishment of natural energy promotion law has been actively discussed in Japan, recently and continuous and efficient application plan of biomass based on abundant technical skill is promoted. In Korea, a lot of researches, for renewable energy are being carried out, and the researches relating to forest biomass is widely known as the only one that can sink carbon is continuously being processed (Ministry of Environment, 2008).

Therefore, the concern about the effective utilization of forest biomass produced by the silviculture is increasing (Son, 2007a; Sim et al., 2006). However, it is reported that only about $12 \%$ of silviculture materials was

${ }^{1}$ Department of Forest Management, College of Forest and Environmental Sciences, Kangwon National University, Korea

* Corresponding author(E-mail: jslee72@kangwon.ac.kr) collected. In addition, a collecting rate of thinning materials was $33 \%$ of total thinning quantity in the last 5 years. Collecting works performed in stems, and other forest residues were wasted in the field (Korea Forest Service, 2010a). OECD countries were required statistical data of forest carbon stock, but no information was produced now in Korea (Korea Forest Service, 2009). As renewable energy use increases based on government policy, long-term timber production and supply plan is required for stable production of biomass (Korea Forest Service, 2010a).

To cope with these problems, the application of GIS to the estimation of forest biomass potential is recent. Previous studies have conducted that the amount of biomass demand and supply at the large scale can be estimated (Emer et al, 2010; Koopmans, 2005; Ranta, 2005; Masera et al., 2006). Lee et al. (2009) and Kinosita (2009) conducted a spatial evaluation of forest biomass usage and Ranta (2005) analyzed availability of logging residues from regeneration felling for biofuel production. In recent years, additionally to forest bioenergy potential of forest residues, Lopez-Rodriguez et al. (2009) performed spatial assessment of the bioenergy potential focusing on province level. In addition to this, Emer et al. (2010) and Rorstad et al. (2010) estimated the woody biomass supply and demand in sub-national scale.

Much of these research focuses on usages of forest biomass with regional level has been less common, there will come potential regional level. One of the major problems of forest biomass supply is the sustainability associated to forest management activities. It is therefore necessary to bring forest biomass that is dependent on forest management plan, into a condition when and whereby they produce forest product in regional level (Lee et al., 
2009). It is important to clarify the analysis of the demand-supply balance of forest bioenergy will be need for the wood energy application plan.

The objectives of our study are to 1) estimate the quantity and identify the spatial distribution of forest biomass; 2) analyze the demand and supply of forest bioenergy use by forest management planning; 3) discuss the efficiency of this approach with respect to bioenergy monitoring.

\section{METHOD}

\section{Study area}

The study areas were Yongdong region (Goseong (GS), Yangyang (YY), Gangneung (GN), and Samcheok (SC) in Gangwon province (Fig. 1). An area of GS, YY, GN, and SC were 64,429 ha, 62,875 ha, 104,078 ha, and 118,552 ha, respectively. Administrative district is composed of Eup and Myeon. Eup and Myeon are determined by the number of population. Eup has a population over 20,000 and Myeon has a population less than that of Eup. The commercial forest (CF) districts are about $22 \%$ of total area in Yongdong. CF district is selected by Korea Forest Service for primarily producing timber. Sixtyfour percent of forest type in CF is covered with coniferous forest and $34 \%$ is covered with three age class (1class=10years). Meanwhile, recent silviculture area of GS, YY, GN, SC were 5.9\% (2,634 ha), 7.4\% (3,987 ha), $5.5 \%$ (4,580 ha), 7.0\% (7,248 ha) respectively. But more efficient and sustainable forest management is needed (Gangwon, 2007).

GIS data for analyzing the spatial characteristics was

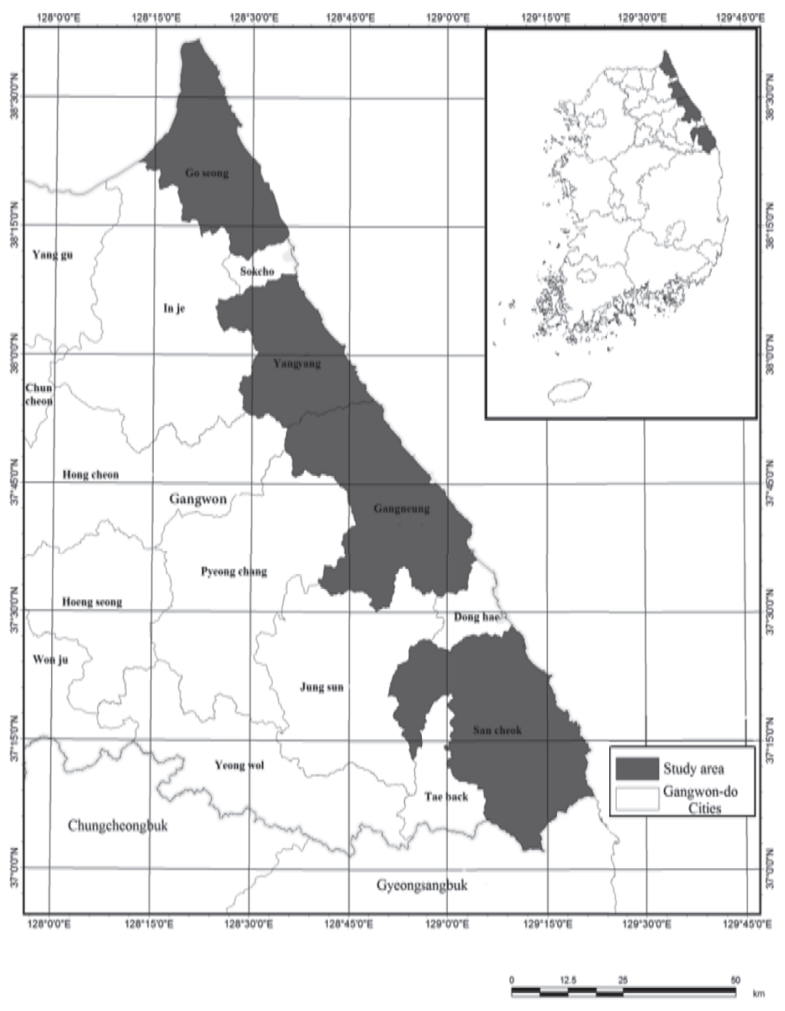

Fig. 1. Location of study area. composed of compartment, economic-forest border, administrative border, forest type (4th), and road networks. GIS (Geographic information system) data was provided by the Korea Forest Service and the National Geographic Information Institute (Table 1). Administrative data included thinning and silviculture document (Goseong, 2008; Yangyang, 2008; Gangneung, 2008; Samcheok, 2008) and population and housing census statistics (Statistics Korea, 2005). The census statistics provided the number of detached house in each City. ESRI's ArcGis 9.3 was used to analyze the spatial patterns.

\section{Conventional data and processing}

With Conducting the analysis of potential biomass shows figure 2. We first construct the GIS database using FGIS (forest GIS) and administrative database. Census statistics and FGIS data were applied to calculate the potential quantity of biomass demand and that of available biomass. Kinoshita (2009) and Masera et al. (2006) conducted spatial distribution of potential demand using the sector by user (e.g. household) and by area (e.g. rural, urban). Kim and Choi (2009) analyzed the potential demand using by the number of house. Thus, Potential quantity of energy demand was calculated based on the energy consumption of house per hour and annual heating hours (Formula 1).

Potential quantity of energy demand (ton) = the number of detached house $\times$ energy consumption of house per hour ${ }^{1)} \times$ annual heating hours ${ }^{2)} \ldots$ (1)

1) Energy consumption of house per hour (Kcal): 19,800 kcal per $99\left(\mathrm{~m}^{3}\right)$

2) Heating hours: 8 hours a day during 5 month

Commercial-forest district map and numerical forest type map of FGIS and silviculture planning data were applied to estimate the potential quantity of available biomass. Forest tending area was defined as the region of thinning and natural silviculture at from II to IV age class (Korea Forest Service, 2000). Stand volume was calculated by forest type with age class (Korea Forest Service, 2005). Biomass expansion factor and basic wood density $\left(\mathrm{t} / \mathrm{m}^{3}\right)$ were taken from the guideline of IPCC

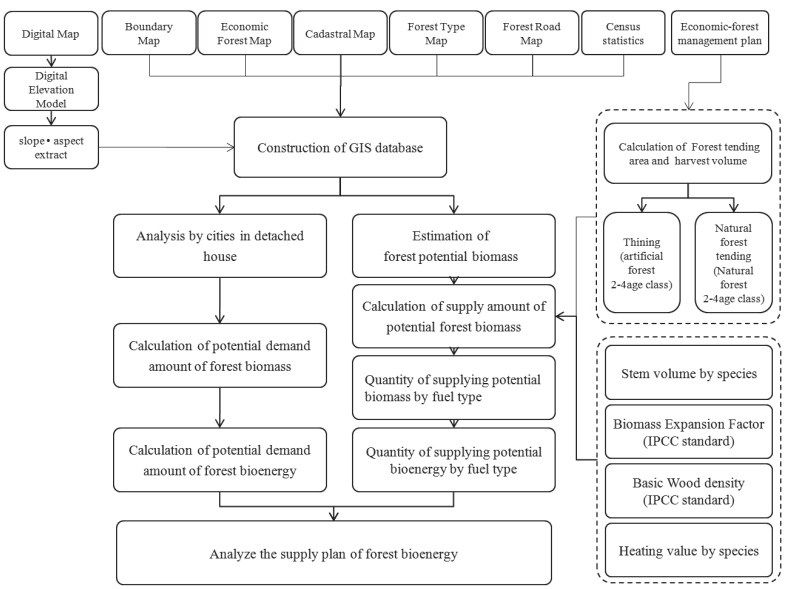

Fig. 2. Method. 
Table 1. GIS data for study area

\begin{tabular}{|c|c|c|c|}
\hline Map & Properties & Scale & Provider \\
\hline 4th Forest type Map & Forest type, Age class, diameter class, crown density & $1: 25,000$ & Korea Forest Service \\
\hline Administrative district Map & City, Eup and Myeon boundary & $1: 25,000$ & Korea Forest Service \\
\hline Economic forest (EF) Map & EF boundary & $1: 25,000$ & Korea Forest Service \\
\hline Forest road Map & Road and forest road & $1: 25,000$ & Korea Forest Service \\
\hline Topographical Map & Contour & $1: 25,000$ & National Geographic Information Insitute \\
\hline
\end{tabular}

Table 2. Regional expansion factors by the IPCC standard

\begin{tabular}{lcc}
\hline Division & Conifers & Non conifers \\
\hline Biomass Expansion Factor $(\mathrm{x}+\mathrm{y}+\mathrm{z})$ & 1.70 & 1.80 \\
Rate of aboveground biomass $(\mathrm{x})$ & 0.32 & 0.46 \\
Rate of stem volume (y) & 0.38 & 1 \\
Rate of underground biomass (z) & 0.29 & 0.34 \\
Rate of aboveground and underground biomass $(\mathrm{R}=(\mathrm{z}) /(\mathrm{x}+\mathrm{y}))$ & 0.45 \\
Basic Wood density & & 0.73 \\
Tree-top and Branch Ratio & & 0.23 \\
\hline
\end{tabular}

(Intergovernmental Panel on Climate Change).

Utilization factor were applied to calculate the estimate the quantity of available biomass. This factor was determined by treetop and branch in aboveground biomass except stem. Tree is classified into three parts (treetop, branch, root collar) except stem, and rate of each part were reported as 55:18:26 (Siraisi, 2001). Therefore, the value of utilization factor was applied to 0.73 (Table 2). And, average thinning rates used was $30 \%$ based on the standards of forest thinning, and collecting rates used was $10 \%$ based on the average collecting rates for 10 years in Gangwon province (Gangwon, 2008).

Quantity of available biomass by forest silviculture plan $=$ forest tending area $(\mathrm{ha})^{1)} \times$ Stem-volume $\left(\mathrm{m}^{3} /\right.$ ha) ${ }^{2)} \times$ Aboveground biomass expansion factor ${ }^{3)} \times$ utilization factor ${ }^{4)} \times$ Basic Wood density $\left(\mathrm{t} / \mathrm{m}^{3}\right)^{5)} \times$ rates of thinning $\times$ rates of collection ......(2)

1) Forest tending area (ha): The areas were calculated by the forest silviculture plan.

2) Stem-volume $\left(\mathrm{m}^{3} / \mathrm{ha}\right)$ : Volume of forest per ha $\left(\mathrm{m}^{3}\right)$

3) Aboveground biomass expansion factor: expansion factor of Aboveground except Root Rate

4) Utilization factor: The rate of top-tree and branch in aboveground biomass except stem and root

5) Basic Wood density $\left(\mathrm{t} / \mathrm{m}^{3}\right)$ : Rates of Dry weight for Volume

Potential forest bioenergy produced from the forest silviculture plan was compared by fuel types (wood chip boiler and wood pellet boiler). Forest bioenergy was calculated by multiplying the forest biomass with conversion factor and caloric value (formula 3 and 4). Choi et $a l$. (2009) provided the conversion factor of fuel type and caloric value.

Potential forest biomass energy (wood chip) = forest biomass (ton) $\times$ wood chip conversion factor ${ }^{1)} \times$ low caloric value of chip boiler $(\mathrm{kcal} / \mathrm{kg})^{2)}$

Potential forest biomass energy (wood pellet) $=$ forest biomass (ton) $\times$ wood pellet conversion factor ${ }^{3)} \times$ low caloric value of pellet boiler $(\mathrm{kcal} / \mathrm{kg})^{4)}$

1) Wood chip conversion factor: 0.7

2) Low caloric value of chip boiler: $3,060 \mathrm{kcal} / \mathrm{kg}$

3) Wood pellet conversion factor: 0.6

4) Low caloric value of pellet boiler: $3,870 \mathrm{kcal} / \mathrm{kg}$

Finally, the quantity of bioenergy demand by detached house was compared with the quantity of forest bioenergy supply by fuel form to analyze the energy supply rate. Also, the quantity of biomass energy supply was analyzed for multiple years.

\section{RESULT AND DISCUSSION}

\section{The number of houses and the quantity of energy demand}

Distribution of house

The total number of houses was about 55,000 in four City areas, and the number of detached houses was about 40,000 which represent $74 \%$ the total number of house. The average number of houses in Cities was about 13,800. GN had the highest number of houses. The average number of detached houses in City was 10,200. GN also showed the highest number of detached house. SC (over 90\%) showed the highest detached house rates. Study areas showed larger differences in the number of population than in the number of houses among them. Jumunjin-Eup, GN showed the largest number of house (about 7,600) in 4 Cities. But, Singi-Myeon, Sam cheok had less than $1 \%$ of houses. Number of detached house had similar a trend with the total number of house.

Distribution of the demand for potential bioenergy 
Table 3. Quantity of potential demand of houses by district in Yongdong region

\begin{tabular}{|c|c|c|c|c|c|}
\hline \multirow[b]{2}{*}{ City } & \multirow[b]{2}{*}{ Town } & \multicolumn{2}{|c|}{ The number of houses } & \multirow{2}{*}{$\begin{array}{c}\text { Rate of detached } \\
\text { house(B/A) } \\
(\%)\end{array}$} & \multirow{2}{*}{$\begin{array}{l}\text { Quantity of } \\
\text { potential } \\
\text { demand } \\
\text { (Gcal) }\end{array}$} \\
\hline & & $\begin{array}{l}\text { Total house } \\
\text { (A) }\end{array}$ & $\begin{array}{l}\text { Detached house } \\
\text { (B) }\end{array}$ & & \\
\hline \multirow{9}{*}{ GN } & Gangdong-Myeon & 2,032 & 1,815 & 89.3 & 43,124 \\
\hline & Gujeong-Myeon & 1,316 & 1,312 & 99.7 & 31,173 \\
\hline & Sacheon-Myeon & 1,649 & 1,408 & 85.4 & 33,454 \\
\hline & Seongsan-Myeon & 1,171 & 1,098 & 93.8 & 26,088 \\
\hline & Yeongok-Myeon & 2,147 & 1,422 & 66.2 & 33,787 \\
\hline & Okgye-Myeon & 2,113 & 1,575 & 74.5 & 37,422 \\
\hline & Wangsan-Myeon & 834 & 834 & 100 & 19,816 \\
\hline & Jumunjin-Eup & 7,692 & 4,588 & 59.6 & 109,011 \\
\hline & Total & 18,954 & 14,052 & 83.6 & 333,875 \\
\hline \multirow{6}{*}{ GS } & Ganseong-Eup & 2,797 & 1,419 & 50.7 & 33,715 \\
\hline & Geojin-Eup & 2,989 & 2,685 & 89.8 & 63,796 \\
\hline & Jugwang-Myeon & 1,578 & 1,446 & 91.6 & 34,357 \\
\hline & Toseong-Myeon & 2,409 & 2,266 & 94.1 & 53,840 \\
\hline & Hyeonnae-Myeon & 1,319 & 1,262 & 95.7 & 29,985 \\
\hline & Total & 11,092 & 9,078 & 84.4 & 215,693 \\
\hline \multirow{9}{*}{$\mathrm{SC}$} & Gagok-Myeon & 422 & 421 & 99.8 & 10,003 \\
\hline & Geundeok-Myeon & 2,657 & 2,492 & 93.8 & 59,210 \\
\hline & Nogok-Myeon & 415 & 415 & 100 & 9,860 \\
\hline & Dogye-Eup & 5,029 & 2,663 & 53.0 & 63,273 \\
\hline & Miro-Myeon & 902 & 889 & 98.6 & 21,123 \\
\hline & Singi-Myeon & 351 & 341 & 97.2 & 8,102 \\
\hline & Wondeok-Eup & 2,563 & 2,258 & 88.1 & 53,650 \\
\hline & Hajang-Myeon & 620 & 597 & 96.3 & 14,185 \\
\hline & Total & 12,959 & 10,076 & 90.9 & 239,406 \\
\hline \multirow{7}{*}{ YY } & Ganghyeon-Myeon & 1,759 & 1,353 & 76.9 & 32,147 \\
\hline & Seo-Myeon & 1,244 & 1,107 & 89.0 & 26,302 \\
\hline & Sonyang-Myeon & 1,110 & 875 & 78.8 & 20,790 \\
\hline & YY-Myeon & 4,174 & 1,777 & 42.6 & 42,222 \\
\hline & Hyeonnam-Myeon & 2,159 & 1,420 & 65.8 & 33,739 \\
\hline & Hyeonbuk-Myeon & 1,639 & 954 & 58.2 & 22,667 \\
\hline & Total & 12,085 & 7,486 & 68.6 & 177,867 \\
\hline
\end{tabular}

Table 3 lists the quantity of potential bioenery demand estimators for each district. The quantity of total annual energy demands in 4 Cities was about 960,000 Gcal based on the number of detached house. Average quantity of annual energy demand of city was about 240,000 Gcal, and average quantity of annual energy demand of GN, SC, GS, and YY was respectively about 330,000 Gcal, 240,000 Gcal, 210,000 Gcal, and 180,000 Gcal. Especially, the quantity of energy demand in GN was $47 \%$ higher than those of YY.

Jumunjin-Eup, GN had the largest quantity of energy demand (110,000 Gcal), but Singi-Myeon, SC had the lowest energy demand (8,000 Gcal). Quantity of total energy demand at Myeon was about 640,000 Gcal which was $48 \%$ higher than Eup areas. The average of the total energy demand of detached house in Eup was higher about 44\% than that of Myeon (Table 3, Fig. 3). Several studies (Kinoshita, 2009; Masera et al., 2006; Emer et al., 2010) have illustrated the spatial distribution of forest biomass demand using census data. Our results also enable us to estimate the potential biomass demand on households with local and regional scale.

\section{Estimation of potential forest biomass quantity}

The distribution of harvest area and volume by commercial-forest management plan

Total area of forest tending for 10 years was about 67,000 ha, which was $87 \%$ of CF area in 4 Cities. Eighty- 

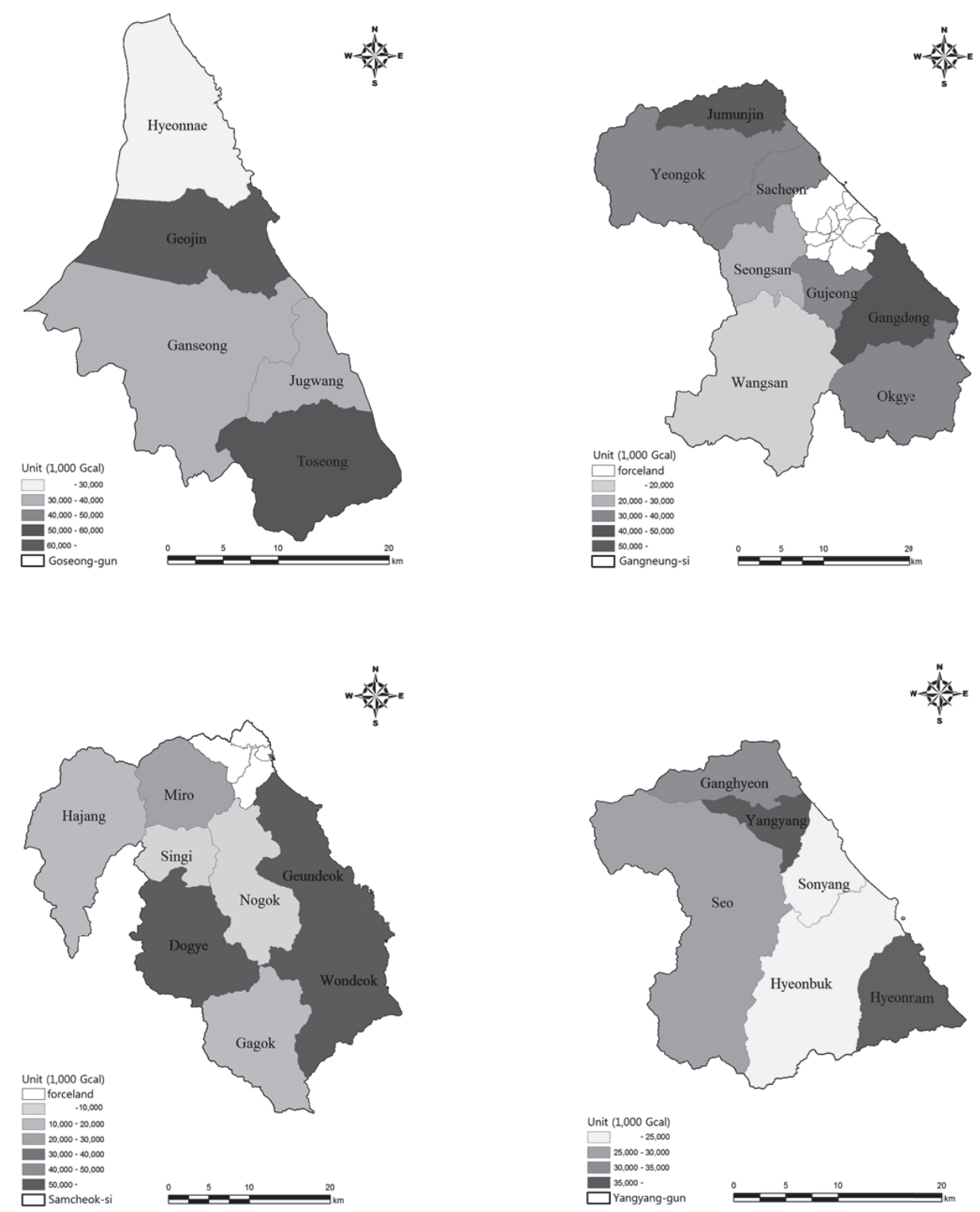

Fig. 3. The distribution map for the quantity of potential demand with the number of detached house.

five percentage of silviculture planning was conducted at III, IV age class. GN had the largest size of forest tending area, and SC had the smallest area. But, GS had the largest volume of harvest and YY had the smallest volume of that. The area of forest tending in GN was larger than GS about 600 ha. However, the area of forest tending plan in III, IV age class in GS was larger than GN about 2,000 ha. And difference in total volume of harvest was $250,000 \mathrm{~m}^{3}$ (Table4).

\section{The distribution of potential forest biomass}

Previous studies have analyzed for several biomass models in estimating regional supply of harvest residues (Rorstad, 2010; Tsuguki et al., 2009) and WISDOM model (Masera et al., 2006), which can be used to predict the woodfuel supply spatial pattern using GIS. The results provided the potential available biomass on the forest resources and management planning in targeted Yongdong region. Also, it provided data for where the

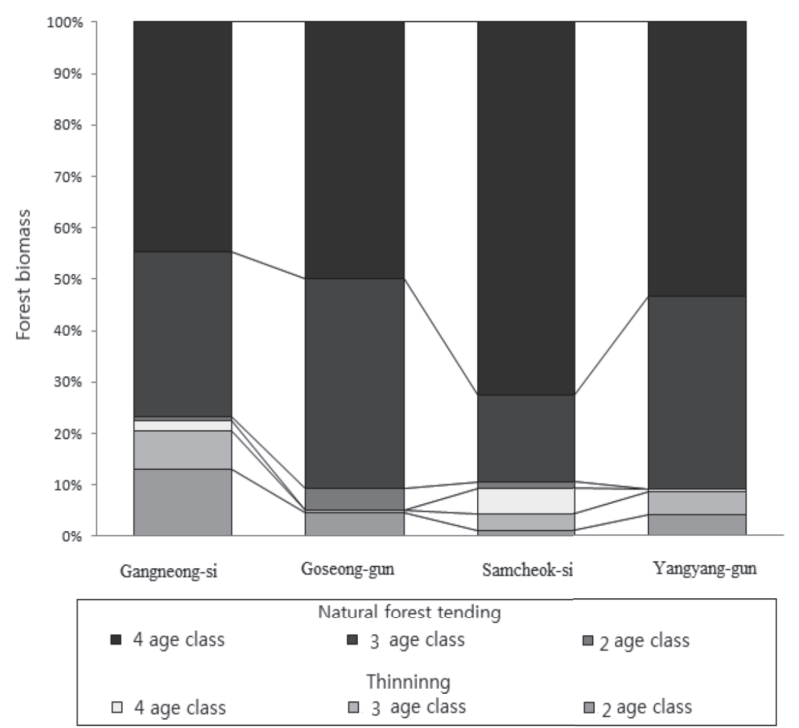

Fig. 4. Quantity of potential forest biomass by tending type and age class. 
biomass produced or how much it could be produced.

Total quantity of forest biomass supply was 40,646 ton from the silviculture planning for 10 years, and average value per ha was 0.53 ton. Quantity of forest biomass in cities had a similar trend with the quantity of silviculture harvest. GS had the highest quantity of biomass supply about 13,000 ton. Average quantity of biomass per ha in SC, YY, GS, and GN was 0.69 ton, 0.61 ton, 0.60 ton, and 0.55 ton respectively. Quantity of forest biomass in Eup was 31\% lower than Myeon. But, the difference of the quantity of biomass per ha between the Eup and Myeon is marginal (Table 4).
Table 4. Available potential forest biomass on cities by forest silviculture planning

\begin{tabular}{cccc}
\hline City & $\begin{array}{c}\text { Forest } \\
\text { tending area } \\
(\text { ha) }\end{array}$ & $\begin{array}{c}\text { Harvest } \\
\text { volume } \\
\left(\mathrm{m}^{3}\right)\end{array}$ & $\begin{array}{c}\text { Available forest } \\
\text { biomass } \\
\text { (ton) }\end{array}$ \\
\hline GN & 21,718 & $3,378,464$ & 12,064 \\
GS & 21,158 & $3,628,285$ & 12,726 \\
SC & 12,216 & $2,202,930$ & 8,398 \\
YY & 12,262 & $2,136,976$ & 7,458 \\
\hline Total & 67,354 & $11,346,655$ & 40,646 \\
\hline
\end{tabular}

Table 5. Quantity of supplying potential biomass and bioenergy by fuel forms for 10 year

\begin{tabular}{|c|c|c|c|c|c|}
\hline \multirow[t]{2}{*}{ City } & \multirow[t]{2}{*}{ Town } & \multicolumn{2}{|c|}{$\begin{array}{l}\text { The supplying potential } \\
\text { biomass (ton) }\end{array}$} & \multicolumn{2}{|c|}{$\begin{array}{l}\text { The supplying potential } \\
\text { bioenergy (Gcal) }\end{array}$} \\
\hline & & Chip & Pellet & Chip & Pellet \\
\hline \multirow{9}{*}{ GN } & Gangdong-Myeon & 1,438 & 1,230 & 4,400 & 4,760 \\
\hline & Gujeong-Myeon & 276 & 236 & 845 & 914 \\
\hline & Sacheon-Myeon & 673 & 575 & 2,058 & 2,227 \\
\hline & Seongsan-Myeon & 1,016 & 869 & 3,110 & 3,365 \\
\hline & Yeongok-Myeon & 720 & 616 & 2,205 & 2,385 \\
\hline & Okgye-Myeon & 2,146 & 1,836 & 6,566 & 7,105 \\
\hline & Wangsan-Myeon & 1,547 & 1,324 & 4,734 & 5,123 \\
\hline & Jumunjin-Eup & 615 & 526 & 1,883 & 2,037 \\
\hline & Total & 8,431 & 7,212 & 25,801 & 27,916 \\
\hline \multirow{6}{*}{ GS } & Ganseong-Eup & 3,299 & 2,823 & 10,096 & 10,923 \\
\hline & Geojin-Eup & 1,856 & 1,588 & 5,679 & 6,145 \\
\hline & Jugwang-Myeon & 661 & 565 & 2,022 & 2,187 \\
\hline & Toseong-Myeon & 2,248 & 1,924 & 6,880 & 7,444 \\
\hline & Hyeonnae-Myeon & 836 & 715 & 2,558 & 2,768 \\
\hline & Total & 8,900 & 7,615 & 27,235 & 29,467 \\
\hline \multirow{9}{*}{$\mathrm{SC}$} & Gagok-Myeon & 186 & 160 & 571 & 617 \\
\hline & Geundeok-Myeon & 1,069 & 914 & 3,270 & 3,538 \\
\hline & Nogok-Myeon & 1,558 & 1,333 & 4,769 & 5,160 \\
\hline & Dogye-Eup & 205 & 175 & 627 & 679 \\
\hline & Miro-Myeon & 427 & 366 & 1,308 & 1,415 \\
\hline & Singi-Myeon & 426 & 365 & 1,304 & 1,411 \\
\hline & Wondeok-Eup & 290 & 248 & 886 & 959 \\
\hline & Hajang-Myeon & 1,704 & 1,458 & 5,214 & 5,642 \\
\hline & Total & 5,865 & 5,019 & 17,949 & 19,421 \\
\hline \multirow{7}{*}{ YY } & Ganghyeon-Myeon & 30 & 26 & 93.239 & 100.881 \\
\hline & Seo-Myeon & 967 & 827 & 2,959 & 3,202 \\
\hline & Sonyang-Myeon & 832 & 712 & 2,547 & 2,756 \\
\hline & Yangyang-Myeon & 386 & 330 & 1,182 & 1,279 \\
\hline & Hyeonnam-Myeon & 1,439 & 1,231 & 4,402 & 4,763 \\
\hline & Hyeonbuk-Myeon & 1,559 & 1,334 & 4,770 & 5,161 \\
\hline & Total & 5,213 & 4,460 & 15,953 & 17,262 \\
\hline Total & & 28,409 & 24,306 & 86,938 & 94,066 \\
\hline
\end{tabular}


Coniferous forest had about 25\% higher biomass occurrences than deciduous or mixed forests. Thinning was $14 \%$ in the distribution of occurrence by forest tending, but natural forest silviculture was 86\%. Especially, fifty-three percent of thinning was applied to the artificial forests with II age class which contained 6\% of total biomass quantity. But, sixty-one percent of natural forest tending was applied to the natural forests with IV age class which had 54\% of total biomass quantity.

Forest tending area for thinning on the artificial forest was larger than the deciduous forest area. But because most age class distribution was less than III age class in artificial forest, the potential quantity of energy could be produced in natural forest tending area (Fig. 4). Son et al. (2007a) were reported that total of forest biomass in natural forest was larger than artificial forest area in national level. Our result showed that similar tendency that available potential biomass was mainly produced by natural forest tending in regional level. These results suggest that if the natural forest tending area were to increase, the quantity of available biomass would be increased.

The quantity of potential supply of forest bioenergy by fuel form

The comparison of forest biomass quantity by fuel form

The total quantity of potential supply for the forest biomass by chip and pellet was respectively about 28,000 ton and 24,000 ton, and the available quantity of biomass per ha by chip and pellet was 0.37 ton and 0.31 ton respectively. GS showed the highest potential quantity of supply for the forest biomass about $31 \%$ of total quantity of occurrence in City, and the quantity of chip and pellet in GS was about 8,900 ton and about 7,600 ton respectively. And GN was 30\%, SC was $21 \%$, YY was $18 \%$ in order. SC had the highest potential quantity of supply for forest biomass per ha of chip ( 0.48 ton) and pellet (0.41 ton).

\section{The quantity offorest bioenergy by fuel form}

The available quantity of supply for the forest biomass energy of chip was about 86,000 Gcal, and on average 1.29 Gcal per ha could be supplied. And pellet could supply 94,000 Gcal of forest biomass energy, which is $1.40 \mathrm{Gcal}$ per ha. If products of silviculture were used to produce chip fuels, quantity of biomass per ha would be $17 \%$ higher than that of pellet. If the quantity of energy generated from various fuel forms were compared, pellet boiler would show $8 \%$ higher than others (Table 5 ).

GS had the highest quantity of supply for forest biomass energy, and chip could provide 27,200 Gcal and pellet could provide 29,500 Gcal, approximately. The quantity of forest biomass energy per ha showed similar trends with the quantity of forest biomass in cities (Fig. 5 and Fig. 6). The energy from chip and pellet was the highest in SC, which are the value of 1.47 Gcal per ha and $1.59 \mathrm{Gcal}$ per ha respectively. Nogok-Myeon, SC had the highest quantity of forest bioenergy per ha, and it was about $42 \%$ higher than the lowest area, Jugwang-
Myeon in GS.

\section{The Calculation of supply rate of forest bioenergy}

The supply rate of forest bioenergy for cities was about $1 \%$, and differences of energy supply rate based on fuel forms were $0.08 \%$. GS had the highest supply rate of chip in city about $1.26 \%$, and YY, GN, and SC were $0.90 \%, 0.77 \%, 0.75 \%$ respectively. Also, supply rate for pellet showed similar trends with chip form (Table 6)

According to the analysis in Eups, Nogok-Myeon in SC had the highest value of $4.8 \%$ in chip and 5.2\% in pellet, and the supply rate was 3\% higher than in other areas. Supply rate in Wangsan-Myeon in GN, HajangMyeon in SC, Hyeonbuk-Myeon in YY was 2\% higher than others. But, Jumunjin-Eup in GN, Dogye-Eup in SC, Ganghyeon-Myeon in YY showed less than $0.2 \%$ of energy supply rate (Table 6). if the standards of Son et al. (2007a; 2007b) were applied as the biomass expan-

Table 6. Rate of supply potential energy on cities

\begin{tabular}{|c|c|c|c|}
\hline \multirow[t]{2}{*}{ City } & \multirow[t]{2}{*}{ Town } & \multicolumn{2}{|c|}{$\begin{array}{c}\text { Rate of supplying potential } \\
\text { bioenergy } \\
\text { by fuel form }(\%)\end{array}$} \\
\hline & & Chip & Pellet \\
\hline \multirow{8}{*}{ GN } & Gangdong-Myeon & 1.0 & 1.1 \\
\hline & Gujeong-Myeon & 0.3 & 0.3 \\
\hline & Sacheon-Myeon & 0.6 & 0.7 \\
\hline & Seongsan-Myeon & 1.2 & 1.3 \\
\hline & Yeongok-Myeon & 0.7 & 0.7 \\
\hline & Okgye-Myeon & 1.8 & 1.9 \\
\hline & Wangsan-Myeon & 2.4 & 2.6 \\
\hline & Jumunjin-Eup & 0.2 & 0.2 \\
\hline \multirow{5}{*}{ GS } & Ganseong-Eup & 3.0 & 3.2 \\
\hline & Geojin-Eup & 0.9 & 1.0 \\
\hline & Jugwang-Myeon & 0.6 & 0.6 \\
\hline & Toseong-Myeon & 1.3 & 1.4 \\
\hline & Hyeonnae-Myeon & 0.9 & 0.9 \\
\hline \multirow{8}{*}{$\mathrm{SC}$} & Gagok-Myeon & 0.6 & 0.6 \\
\hline & Geundeok-Myeon & 0.6 & 0.6 \\
\hline & Nogok-Myeon & 4.8 & 5.2 \\
\hline & Dogye-Eup & 0.1 & 0.1 \\
\hline & Miro-Myeon & 0.6 & 0.7 \\
\hline & Singi-Myeon & 1.6 & 1.7 \\
\hline & Wondeok-Eup & 0.2 & 0.2 \\
\hline & Hajang-Myeon & 3.7 & 4.0 \\
\hline \multirow{6}{*}{$\mathrm{YY}$} & Ganghyeon-Myeon & 0.0 & 0.0 \\
\hline & Seo-Myeon & 1.1 & 1.2 \\
\hline & Sonyang-Myeon & 1.2 & 1.3 \\
\hline & Yangyang-Myeon & 0.3 & 0.3 \\
\hline & Hyeonnam-Myeon & 1.3 & 1.4 \\
\hline & Hyeonbuk-Myeon & 2.1 & 2.3 \\
\hline
\end{tabular}



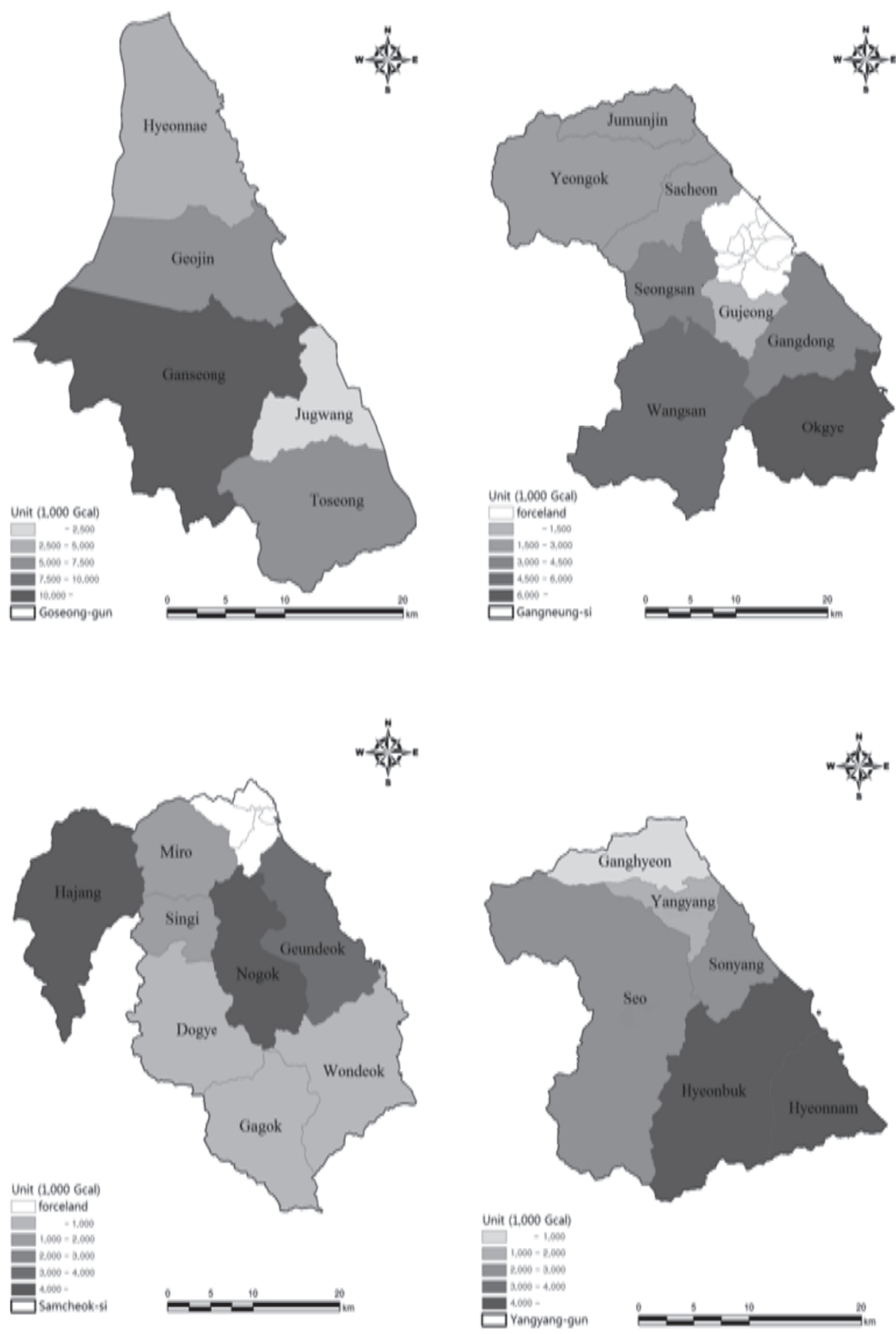

Fig. 5. The distribution map for the quantity of supplying potential bioenergy by chip.

sion factor and basic wood density of trees, average annual rates of bioenergy for chip and pellet were both less than $1 \%$. And the supply rate of bioenergy in 4 Cities was about $10 \%$ lower than IPCC standards.

Currently, forest silviculture showed $10 \%$ of collecting rate, and Korean ministry of forest (2009) made a goal to improve the rates to $60 \%$ by 2017 . If the collecting rate for forest residues after silviculture could increase from $10 \%$ to $60 \%$ based on the annual report of Korea Forest Service (2010a), the supply rates of energy could increase to $7.5 \%$. Meanwhile, Korea Forest Service (2010) had been constructing carbon circulation villages using forest biomass until 2014. SC are recommended for the target areas.

\section{CONCLUSION}

The potential quantity of supply and demand for forest bioenergy was investigated using a GIS-based analysis with on FGIS and forest planning information. The distribution and availability of forest bioenergy was analyzed an time series, and the rate of supply in the selected region was estimated.

The average of the total energy demand of detached house in Eup was higher than that of Myeon. Quantity of forest biomass in Eup was lower than Myeon. But a quantity of biomass per ha in Eup was higher. The quantity of biomass per ha from the chip fuel was 17\% higher than that of pellet. But, if the quantity of bioenergy gen- 

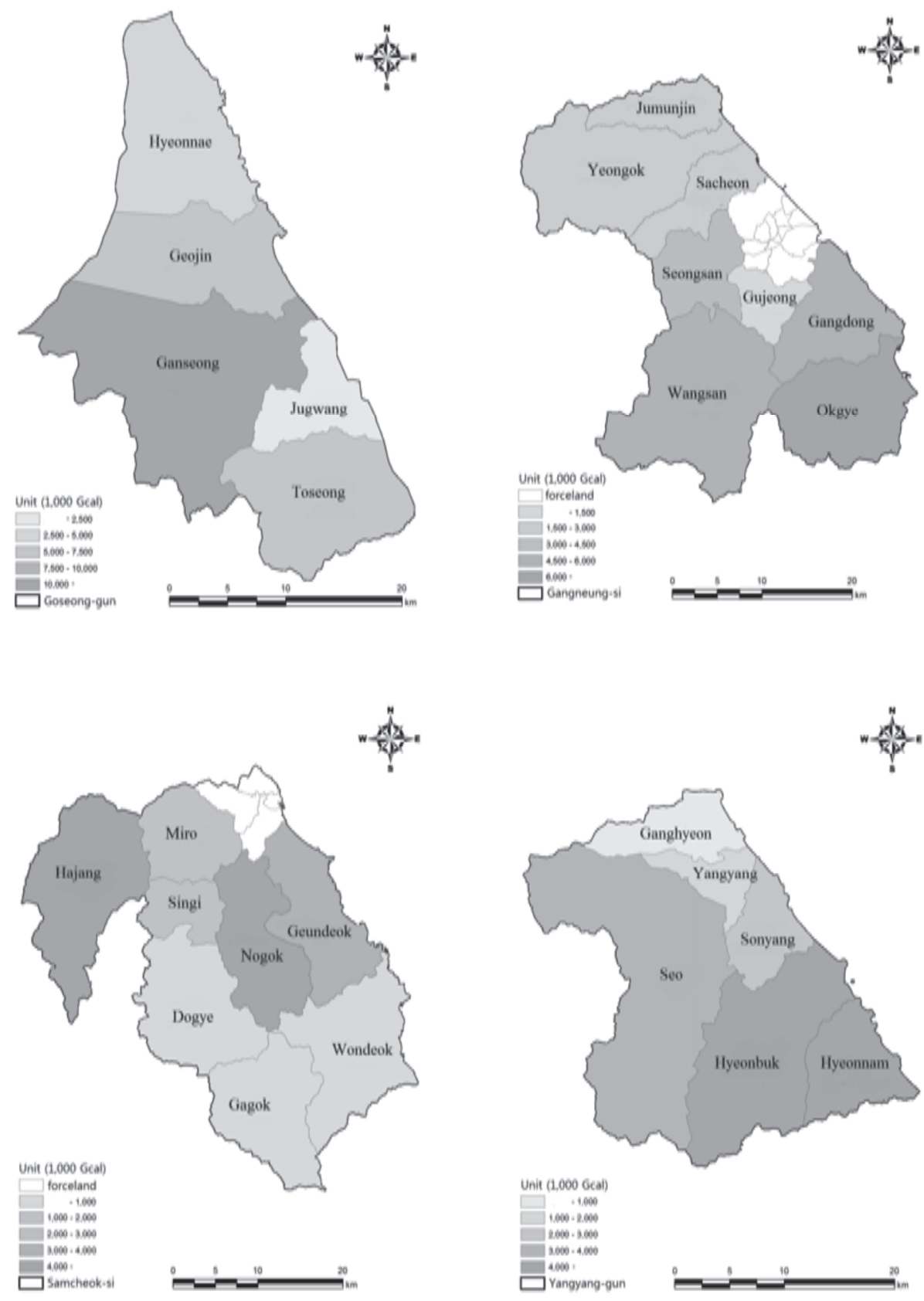

Fig. 6. The distribution map for the quantity of supplying potential bioenergy by pellet.

erated from various fuel forms were compared, pellet boiler was showed $8 \%$ higher than others.

The supply rate of forest bioenergy was about $0.7 \%$ to $1.4 \%$, and differences of energy supply rate based on fuel forms were $0.08 \%$. If the collecting rate for forest residues after silviculture could increase from $10 \%$ to $60 \%$, the supply rates of energy could increase to $7.5 \%$.

In Korea, the self-sufficiency rate against the total consumption of wood in 2009 was low being 12\% (Korea Forest Service, 2010b). In addition, most of unused woods such as treetop, branch was left in forest. Sometimes, they cause fires or produce massive cleaning costs during the rainy season. Using forest residues as the renewable energy sources could increase the rate of self-sufficiency in energy and the efficiency of forest management in the future. The use of GIS will improve the efficiency of monitoring forest resources, and also provide basic data for the wood energy application plan.

\section{ACKNOWLEDGEMENTS}

This study was carried out with the support of 'Forest Science \& Technology Projects (Project No. S110910L060120)' provided by Korea Forest. 


\section{REFERENCES}

Choi, Y. S., J. S. Kim and D. S. Cha 2009 Comparison of efficiency for wood fuels (Chips and Pellets) by life cycle assessment. Journal of Korea Forest Society, 98(3): 426-434

Emer, B., S. Grigolato, D. Lubello and R. Cavalli 2010 Comparision of biomass feedstock supply and demand in Northeast Italy. Biomass and Bioenergy, Doi:10.1016/j.biombioe.2010.09.005

Gangneung 2008 Management plan of economic forest in Gangneung. Kangwon Univ. Press, Cheonchun (Korea) pp. $135-240$

Gangwon. 2007 Administration Statistics sourcebook, Gangwon pp. 218-219

Goseung. 2008 Management plan of economic forest in GoSeong. Kangwon Univ. Press, Cheonchun (Korea) pp. 139176

Kim, J. S. and Y. S. Choi 2009 Analysis Social economics of Wood Fuels and Fossil Fuel Emission. Proceeding of annual conference of Korea Forest Society 2009. pp. 536-538

Koopmans, A. 2005 biomass energy demand and supply for South and South-East Asia-assessing the resource base. Biomass and Bioenergy, 28: 133-150

Kinoshita, T., Inoue, K., Iwao, K., Kagemoto, H. and Y. Yamagata 2009 A Spatial evaluation of forest biomass usage using GIS. Applied Energy 86: $1-8$

Korea Forest Service 2000 Forest and Forestry Technology-III Appendix. Korea Forest Service, Seoul (Korea) pp. 700-715

Korea Forest Service 2005 Standards Manual of Sustainable Forest Resource Management. Korea Forest Service, Seoul (Korea) pp. 81-137

Korea Forest Service 2009 Climate change and forests. Korea Forest Service, Seoul (Korea) pp. 71-75

Korea Forest Service 2010a Optimization plan to increase forest biomass. Korea Forest Service, Seoul (Korea) pp. 3-5

Korea Forest Service 2010b The study of demonstration project for improving. Korea Forest Service, Seoul (Korea) pp. $11-30$

Lee, J. S., H. C. Lee and H. S. Seo 2009 A GIS-based Supply and Demand Potential mapping of Forestry-biomass energy. Journal of Korean forest society, 98(3): 311-318

Lopez-Rodriguez, F., C. P. Atanet, F. C. Blazquez and A. C. Ruiz 2009 Spatial assessment of the bioenergy potential of forest residues in the western province of Spain, Caceres. Biomass and Bioenergy, 33: 1358-1366

Masera, O., A. Ghilardia, R. Drigo. and M. A. Trossero 2006 WISDOM: A GIS-based supply demand mapping tool for woodfuel management. Biomass and Bioenergy, 30: 618-637

Ministry of Environment 2008 Comprehensive master plan for respond of Climate Change (CPCCC). Ministry of Environment, Seoul (Korea) pp. 7-42

No, S. Y. 2008 How to respond for the recent high oil prices in Japan. Energy Management, 82: 70-81

Ranta, T. 2005 Logging residues from regeneration fellings for biofuel production-a GIS-based availability analysis in Finland. Biomass and Bioenergy, 28: 171-182

Rorstad, P. K., E. Tromborg, E. Bergseng and B. Solberg 2010 Combining GIS and forest modeling in estimating regional supply of harvest residues in Norway. Silva Fennica, 44(3): 435-451

Samcheok 2008 Management plan of economic forest in Samcheok. Kangwon Univ. Press, Cheonchun(Korea) pp. 153248

Sim, C. S. and W. J. Kim 2006 A Feasibility Study of Forest Biomass for a local energy resources in Korea. The Journal of the National academy of sciences, 45: 331-370

Siraisi, J. 2001 The Utility and Foresty of Woody Biomass. Forest biomass energy, 7 : 50-51

Son, Y. M. 2007 The assessment of fossil fuel substitution effect using forest products. Rural and environmental engineering Journal, 95: 144-155

Son, Y. M., J. C. Kim, K. H. Lee and R. H. Kim 2007a Assessment of Forest Biomass in Korea. Korea Forest Research Institute. p. 27

Son, Y. M., K. H. Lee, J. H. Seo and S. D. Kwon 2007b Substitution Effect of Fossil Fuel using Biomass produced by Forest Treatment. Journal of Korea Forest Society, 96(6): 639-643

Statistics Korea 2005 Population and Housing Census. http:// www.nso.go.kr.

Tsuguki T., K. Inoue, K. Iwao, H. kagemoto and Y. Yamagata 2009 A spatial evaluation of forest biomass usage using GIS Applied Energy, 86: 1-8

Yangyang 2008 Management plan of commercial forest in Yangyang. Kangwon Univ. Press, Cheonchun(Korea) pp. 128182 